\section{Non-linear analysis of pile groups}

\author{
F. Basile
}

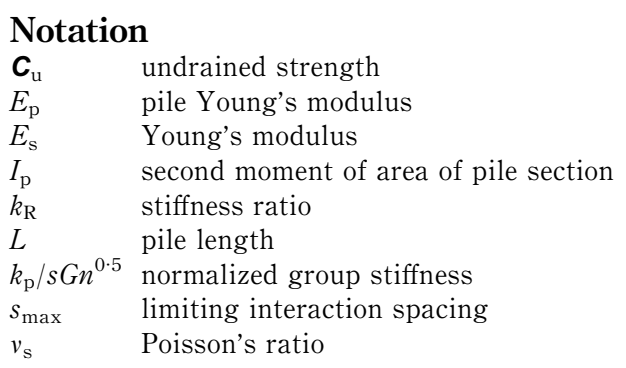

\section{Viggiani, Department of Geotechnical Engineering, University of Napoli Federico II}

The author is to be congratulated for developing a complete boundary element modelling (BEM) solution for the analysis of pile groups under vertical, horizontal and moment loading. The paper provides a benchmark for assessing the accuracy of simplified procedures. For use as a practical engineering tool, however, it suffers some significant limitations.

41. The assumption of a homogeneous elastic half-space or a Gibson soil, though very convenient from the viewpoint of analytical simplicity, is seldom adequate for practical purposes. To quote from Poulos: ${ }^{13}$ 'The major challenge in applying theoretical approaches to practical pile design remains the proper characterization, idealization and geotechnical quantification of the site'. In the writer's experience a proper modelling of the soil profile is one of the key steps of the analysis. For vertical loadings this statement is substantiated by the findings, among others, of Russo and Viggiani ${ }^{29}$ and Mandolini and Viggiani. ${ }^{30}$ For horizontal loadings, the influence of a proper modelling of the subsoil profile is even greater.

42. The assumption of a rigid, free-standing raft may be suited for small pile groups. In this case limitations of mean settlement is the main design requisite, and the settlement is practically unaffected by the load-sharing between piles and raft. If the group is designed according to the traditional capacity-based approach (and this is still the case in the large majority of projects), the actual safety factor is generally high and a linear analysis is satisfactory for practical purposes. ${ }^{31}$

43. In the case of large piled rafts, the flexural stiffness of the raft cannot be but relatively small, and the requisite for an optimum design is the limitation of the mean and the differential settlement. In these cases the assumption of a free-standing, rigid raft is misleading. If the piles are given the role of settle- ment reducers, ${ }^{15,32-34}$ the consideration of nonlinearity is mandatory.

44. A proper use of simplified methods, renouncing analytical completeness in favour of a more satisfactory consideration of the factors controlling the actual behaviour of a piled raft, offers considerable advantages. For instance, a method such as NAPRA ${ }^{35}$ is based on influence factors and limited to vertical loading; therefore it is less satisfactory than PGRoupn from the point of view of completeness and analytical elegance. On the other hand it allows a simple consideration of factors such as subsoil profile, load-sharing between raft and piles, non-linearity, finite flexural rigidity of the raft, etc. It has proved very satisfactory in the back-analysis of a number of case histories. ${ }^{31,34}$

\section{G. Russo, Department of Geotechnical Engineering, University of Napoli Federico II}

In order to properly understand the paper, there are a number of points that should be clarified. These are discussed in the following paragraphs.

46. The example used to prove the accuracy of the non-linear solution for the single pile (Fig. 1 and paragraph 22 of the paper) may be misleading. A soil with a Young's modulus of $1056 \mathrm{MPa}$ is to be classified as a soft rock, such as a tuff or a calcarenite; the use of piles in such a soil may be questionable. This is the reason why a value of the ratio $E_{\mathrm{p}} / E_{\mathrm{s}}$ equal to 30 is realistic. In a more typical case $E_{\mathrm{s}}$ ranges between some units and some tens of $\mathrm{MPa}$, and the ratio $E_{\mathrm{p}} / E_{\mathrm{s}}$ ranges between many hundreds and some thousands. The typical load-settlement curve obtained by an approximate analysis such as that of PGROUPN has necessarily a linear initial branch, extending to the load corresponding to the yield of the first interface element. In the code NAPRA, ${ }^{35}$ for instance, a more realistic hyperbolic load-settlement curve for the single pile is adopted.

47. In Fig. 2(b) of the paper the results of PGROUPN show an increase of group stiffness (i.e. a decrease of settlement) with increasing number of piles; could the author comment on this unexpected trend?

48. The effects of non-linearity on the load distribution between the piles has been reported in a more complete form by Caputo and Viggiani as early as $1984 .^{36} \mathrm{~A}$ similar effect is obtained when the finite flexural stiffness of the raft is considered.
Proc. Instn

Civ. Engrs

Geotech. Engng, 2000, 143, Oct. 241-244

Paper 11745
Paper published: Proc. Instn Civ. Engrs Geotech. Engng, 1999, 137, April, 105-115 
49. The parameters used to obtain Fig. 4 are again very untypical: a soil with a Young's modulus equal to $314 \mathrm{MPa}$ is extremely stiff.

50. To assess the results in Figs. 4 and 5, the following elements are missing.

(a) Value of $N_{c}$

(b) Is a group reduction factor applied to the horizontal bearing capacity?

The same questions arise for the case history reported in paragraph 34 .

51. The author states (paragraph 20) that the pile shaft has been discretized, adopting for each element a height-to-diameter ratio of 2 . According to the writer's experience, ${ }^{37}$ this is quite a rough discretization; hence, the suggestion of the author that 'for practical purposes a coarser discretizing of the piles would be adequate' should be carefully investigated.

52. In paragraphs $36-38$ the statements are somewhat generic and sometimes not entirely true. Indeed, efficient methods of analysis for piled rafts are currently available both in linear and non-linear range. ${ }^{3,38-40}$ The method presented in the paper is certainly appealing from a computational viewpoint, but quite obscure on the side of the soil parameters' choice. The importance of this point is obvious if the method is presented as a 'practical engineering tool'.

\section{Author's reply}

The author thanks the writers for their interest in the paper and for their valuable comments. The appreciation of the work by Professor Viggiani is certainly rewarding.

54. The discussion by Viggiani focused on two main issues

(a) the importance of a proper modelling of the soil profile

(b) the influence of raft contribution in the case of a large piled raft in terms of its interaction with the surrounding soil and its finite flexural stiffness.

55. The writer is, of course, correct in pointing out the crucial role of a proper idealization of the subsoil profile in the analysis and design of piled foundations. Indeed, as stated in the paper, the current PGRoupn model (i.e. the Gibson soil idealization) will be extended to handle multi-layered soils by using either the analytical solution for a layered half-space formulated by Chan $e t a l .{ }^{41}$ or the approximate procedure proposed by Lee and Poulos. ${ }^{42}$

56. As regards the second point, the author agrees that the inclusion of soil-raft interaction effects would add to the value of the work. This may be achieved by using either the approach of Banerjee and Driscoll ${ }^{5}$ or by coupling the BEM algorithm of PGROUPN with a finite-element method approach, following the work of Hain and Lee, ${ }^{43}$ Griffiths et al. ${ }^{44}$ and Russo. ${ }^{45}$ However, it is important to note the following points:

(a) In many instances, the raft is in practice resting on fill or soft ground from which little, if any, benefit can be obtained.

(b) Many analyses of this kind are carried out for bridge piers where the raft effect is of minor importance and the caps are truly rigid.

(c) The complexity of taking into account the effects of raft contribution often exceeds normal design needs.

57. The discussion by Russo raises a number of issues which will be addressed in turn. The author believes that the choice of the numerical simulation shown in Fig. 1 to demonstrate the accuracy of the non-linear solution for axially loaded piles is appropriate. The soil model for this example has been used previously by Jardine $e t$ al. ${ }^{14}$ and the objective of using it in this paper was to compare the PGROUPN results with well-established alternative solutions. This same example has been used as a benchmark by Poulos ${ }^{13}$ in his Rankine Lecture and by Guo and Randolph. ${ }^{46}$ The soil is described by Jardine and colleagues as a stiff low-plasticity clay, although it might more accurately be described as a very stiff formation. A comparable initial value of soil modulus could also be attributable to a dense sand.

58. In so far as the debate about hyperbolic and the PGroupn elastic-perfectly plastic model is concerned, it has been shown by other workers. ${ }^{13,19,23,47,48}$ that the elastic-perfectly plastic model can generate realistic non-linear load-settlement curves to failure as yielding along the interface progresses. There is no doubt that hyperbolic models can also give realistic predictions and indeed where comparisons have been carried out on single piles there is substantial agreement. ${ }^{13}$ Both methods show the importance of having a satisfactory non-linear solution as compared with the previous generation of linear elastic models. However, the author believes there are many attractions in an efficient computational model which deals with pile behaviour on a more fundamental basis.

59. The writer has apparently misinterpreted the relationship between the quantity $\left(k_{\mathrm{p}} / s G n^{0.5}\right)$ and the group settlement in Figs 2(a) and (b): $k_{\mathrm{p}} / s G n^{0.5}$ represents a group stiffness 'normalized' as a function of the size of the group, and its decrease with increasing number of piles does not correspond to an increase of group settlement. Indeed, for the entire range of the curves shown in Figs 2(a) and (b) the group settlement decreases with increasing number of piles. As regards the trend of the normalized group stiffness for pile groups greater than $12 \times 12$ in Fig. 2(b), this is a consequence of 
the introduction of the limiting interaction spacing $s_{\max }$ (refer to equation (7)) which restrains the interaction between the more distant piles, thereby leading to a reduction of the group settlement. This results in an increase of the normalizated group stiffness. It is worth noting that a similar trend may also be depicted in the curve obtained from the Piglet analysis (this may more readily be observed from the original paper by Randolph). ${ }^{15}$ If $s_{\max }$ is not included in the analysis, the group settlement is larger, and this results in a decrease of the normalized group stiffness. In this case, the curve from PGRoupN would approach the limiting stiffness of $4 \cdot 5$.

60 . With respect to the work of Caputo and Viggiani, ${ }^{36}$ the writers are correct to bring up the crucial issue of non-linearity effects on the load distribution in pile groups. However, the numerical procedure proposed by Caputo and Viggiani ${ }^{36}$ has the disadvantages of having to assess empirical constants which define the hyperbolic non-linear relationship and the superposition problems which occur with interaction factors. These two issues will be considered at the end of this discussion. In addition, it is important to point out that the work presented by Caputo and Viggiani is restricted to axial loading.

61. As regards the choice of soil modulus in Fig. 4, the author would like to remark, again, that the objective of this numerical example was to examine the validity and accuracy of PGroupn against published solutions. Most of the published numerical solutions on the subject adopt this same data set. ${ }^{19,20,49-51}$ In order to examine piles commonly encountered in practice, a numerical simulation for $K_{\mathrm{R}}=10^{-4}$ has also been presented.

62 . The writer correctly observes that the value of the bearing capacity factor $\left(N_{\mathrm{c}}\right)$ has not been specified. In evaluating the limiting lateral pressure, $N_{\mathrm{c}}$ has been assumed to increase linearly from 2 at the surface to a constant value of 9 at a depth of three pile diameters and below, much as was originally suggested by Broms. ${ }^{52}$ This assumption is widely accepted in practice. No group reduction factors have been applied to determine the horizontal bearing capacity.

63. The issue of optimal pile shaft discretization has been considered carefully and it is clear that this depends on several factors, including the type of problem which has to be solved, the degree of accuracy required and, most importantly, the numerical framework employed to analyse a given problem. No universal rules can therefore be set.

64. Contrary to the writer's expressed view, the choice of soil parameters for PGROUPN is simple and direct. It is necessary only to define three soil parameters whose physical interpretation is clear-that is, the initial ('low strain')
Young's modulus $E_{\mathrm{s}}$, the Poisson's ratio $v_{\mathrm{s}}$ and the undrained shear strength $\boldsymbol{C}_{\mathrm{u}}$. On the other hand, the load-transfer approach (such as is employed in GRUPPALO and NAPRA) is limited by the questionable assessment of the empirical constants which define the hyperbolic nonlinear relationship - these represent geometric parameters of the hyperbola which may only be derived by back-figuring from the results of pile load tests. However, in many practical situations, it is not possible to carry out such testing, at least in the preliminary stages of design.

65. The interaction factor method (such as is employed in Defrig, Piglet, Gruppalo and NAPRA) neglects continuity through the soil and solves the group problem by merely superimposing the two-pile interaction factors. This approximate approach produces a number of limitations (as discussed in paragraph 5), the most significant of these being an overestimation of interaction effects between piles and hence a prediction of unrealistically high loads at the outer piles of the group. This may result in an overconservative design. In contrast, a complete approach (such as is employed in PGROUPN), by considering the simultaneous presence of all the piles within the soil mass, is able to account for their reinforcing effect, thereby avoiding exaggeration of corner loads in large groups in both the vertical and horizontal senses. Inclusion of non-linearity effects further reduces such a load concentration at the outer piles and produces a more uniform load distribution to the individual piles of the group.

66. Finally, having noted that the approach presented in the paper may be extended to model more complex problems such as multilayered soils and soil-raft interactions, the author hopes that PGROUPN will have a useful role in improving understanding of pile group behaviour and perhaps lead to more effective design techniques.

\section{References}

29. Russo G. and Viggiani C. Some aspects of numerical analysis of piled rafts. Proceedings of the 14th International Conference on Soil Mechanics and Foundation Engineering, Hamburg, 1997, 2, 1125-1128.

30. Mandolini A. and Viggiani C. Settlement of piled foundations. Géotechnique, 1997, 47, No. 4, 791-816.

31. Russo G. and Viggiani C. Factors controlling soil-structure interaction for piled rafts. Proceedings of an International Conference on Soil-Structure Interaction in Urban Civil Engineering, Darmstadt, 1998, vol. 2, pp. 297-321.

32. Burland J. B., Broms B. B. and De Mello V. F. B. Behaviour of foundations and structures. Proceedings of the 9th International Conference on Soil Mechanics and Foundation Engineering, Tokyo, 1997, 2, 495-546. 
33. Burland J. B. Piles as settlement reducers. Pro ceedings of the 22nd Conv. Naz. di Geotecnica, Pavia, 1995, 2, 21-34.

34. Viggiani C. Pile group and piled raft behaviour. Theme lecture. Proceedings of the 3rd Seminar on Deep Foundation on Bored and Auger Piles, Ghent, 1998.

35. Russo G. Numerical analysis of piled rafts. International Journal for Numerical and Analytical Methods in Geomechanics, 1998, 22, 447-493.

36. Caputo V. and Viggiani C. Pile foundations analysis: a simple approach to non linearity effects. Rivista Italiana di Geotecnica, 1984, 18 No. $2,32-51$.

37. Russo G. Interazione Terreno Struttura per Piastre su Pali. PhD thesis, Department of Geotechnical Engineering, University of Napoli Federico II, 1996.

38. Poulos H. G. An approximate numerical analysis of pile-raft interaction. International Journal for Numerical and Analytical Methods in Geomechanics, 1994, 18, No. 2, 73-90.

39. Kuwabara F. An elastic analysis for piled raft foundations in a homogeneous soil. Soils and Foundations, 1989, 29, No. 2, 298-310.

40. Randolph M. F. and Clancy P. Efficient design of piled rafts. Proceedings of the 2nd Seminar on Deep Foundations on Bored and Auger Piles, Ghent, 1993, 119-130.

41. Chan K. S., Karasudhi P. and Lee S. L. Force at a point in the interior of a layered elastic half space. International Journal of Solids and Struc. ture, 1974, 10, 1179-1199.

42. Lee C. Y. and Poulos H. G. Axial response ana lysis of piles in vertically and horizontally nonhomogeneous soils. Computers and Geotechnics, 1990, 9, No. 3, 133-148.

43. Hain S. J. and Lee I. K. The analysis of flexible pile-raft systems. Géotechnique, 1978, 28, No. 1, 65-83.

44. Griffiths D. V., Clancy P. and Randolph M. F. Piled raft foundations analysis by finite elements. Proceedings of the 7th International Conference on Numerical Methods in Geomechanics, Cairns, 1991, 2, 1153-1157.

45. Russo G. Developments in the analysis and design of piled rafts. Workshop on Prediction and Performance in Geotechnical Engineering, Napoli, 1998.

46. Guo W. D. and Randolph M. F. Vertically loaded piles in non-homogeneous media. International Journal for Numerical Analytical Methods in Geomechanics, 1997, 21, 507-532.

47. Poulos H. G. Defrig-Deformation Analysis of Pile Groups. User's Guide. Centre for Geotechnical Research, University of Sidney, 1990.

48. Poulos H. G. Settlement prediction for driven piles and pile groups. Proceedings of a Conference on Vertical and Horizontal Deformations of Foundations and Embankments, College Station, Texas, 1994. Geotechnical Special Publication, Vol. 2, No. 40, 1629-1649.

49. Poulos H. G. Behaviour of laterally loaded piles: II-Pile groups. Journal of the Soil Mechanics Foundation Division, American Society of Civil Engineers, 1971, 97, No. SM5, 733-751.

50. Сноw Y. K. Iterative analysis of pile-soil-pile interaction. Géotechnique, 1987, 37, No. 3, 321333.

51. Burghignoli A. and Desideri A. Analisi di un gruppo di pali sollecitati da forze orizzontali. Rivista Italiana di Geotecnica, 1995, No. 3, 163178.

52. Broms B. B. Lateral resistance of piles in cohesive soils. Journal of the Soil Mechanics and Foundation Division, American Society of Civil Engineers, 1964, 90, No. SM2, 27-63. 